\title{
Kaasavad haridusstrateegiad kaasava hariduse juhtriigis Uus-Meremaal
}

\author{
David Mitchell ${ }^{\mathrm{al}}$ \\ ${ }^{a}$ Canterbury Ülikool
}

\begin{abstract}
Annotatsioon
1989. aastast alates on Uus-Meremaa haridussüsteemis toimunud mitmed ulatuslikud reformid, mille tulemusena on sellest saanud üks kõige enam detsentraliseeritud süsteeme maailmas. Artiklis analüüsitakse, mil määral vastab Uus-Meremaal toimuv kümnele kaasava hariduse tunnusele, milleks on kontseptsioon, paigutamine, õppekava, hindamine, õpetamine, aktsepteerimine, juurdepääs, toetus, ressursid ja juhtimine. Töös antakse neist komponentidest lühiülevaade, mida illustreeritakse näidetega olukorrast Uus-Meremaal, ja jõutakse järeldusele, et kõigi kümne tunnuse poolest on Uus-Meremaa heal järjel.
\end{abstract}

Võtmesõnad: kaasav haridus, erivajadustega lapsed, diferentseeritud õpe, tasemerühmad, hariduskorraldus, hariduspoliitika

\section{Sissejuhatus}

Olen oma varasemates töödes (Mitchell, 2015) kaasavat haridust kirjeldanud mitmekülgse nähtusena, mida saab hinnata kümne tunnuse põhjal: kontseptsioon, paigutamine, õppekava, hindamine, õpetamine, aktsepteerimine, juurdepääs, toetus, ressursid ja juhtimine. Siinses artiklis antakse lühiülevaade nende tunnuste olemusest ning ilmestatakse seda näidetega Uus-Meremaalt.

College of Education, Health and Human Development, University of Canterbury, Private Bag 4800, Christchurch, New Zealand; david.mitchell@canterbury.ac.nz 


\section{Uus-Meremaa lühitutvustus}

Uus-Meremaa on Vaikse ookeani lõunaosas paiknev väike (4,4 miljoni elanikuga) demokraatlik riik. Pindalalt on Uus-Meremaa 257 riigi ja territooriumi seas 76. kohal ehk enam-vähem sama suur kui Briti saared. Riigil on ühekojaline parlamentaarne valitsus ja tavaõigusel põhinev õigussüsteem, mis järgib Inglise mudelit. Sisemajanduse koguproduktiga inimese kohta on riik 47. kohal maailmas, samas jätab 5,9\%ni ulatuv töötuse määr riigi 60. kohale. Ühiskonna tulude jaotuse ebavõrdsuse taset näitav Gini koefitsient oli 2012. aastal 0,33, millega Uus-Meremaa asetus 34 OECD riigi seas 12 . kohale. Riigi sündimuse määr on 2,05 , mis ületab veidi rahvastiku taastootmise taset. Uus-Meremaa on mitmekultuuriline riik, kus 71,2\% elanikest on Euroopa, 14,1\% maoori, 11,3\% Aasia, 7,6\% Vaikse ookeani piirkonna, 2,7\% muud (5,4\% määramata) päritolu. 45,6\% elanikest peab end kristlaseks, $2,1 \%$ hinduks, $1,4 \%$ budistiks ja $1,1 \%$ moslemiks. Muusse usku kuulub 1,4\% elanikest, seevastu 38,5\% inimestest ei tunnista ühtegi religiooni (see teeb kokku rohkem kui 100\% elanikkonnast, sest inimesed võisid valida rohkem kui ühe kategooria) (CIA, 2015).

\section{Uus-Meremaa haridussüsteem}

Uus-Meremaal on kolme tüüpi koole: riigikoolid, integreeritud koolid ja erakoolid. Riigikoolides käib 85\% lastest. Neis koolides óppimine on tasuta, kuigi õppekavaväliste ürituste kulude katmiseks oodatakse ka lapsevanemate toetust. Integreeritud koolides käib vaid veidi üle 10\% lastest. Need on erilist tüüpi koolid, näiteks võib neid hallata mõni religioosne ühendus (nt katoliiklased) või järgitakse neis mõnd erilist haridussuunda (nt Steineri koolkond). Ka neid koole rahastab eelkõige riik, kuid koolid võivad küsida tasu mitmesuguste lisateenuste eest. Erakoolides käib alla $5 \%$ lastest. Neis koolides õppimine on tasuline, kuid 25\% nende rahastusest tuleb siiski riigilt.

Uus-Meremaal on kool kohustuslik kõigile 6-16aastastele lastele, kuigi suurem osa lapsi alustab kooliteed 5 aasta vanuselt. Opppetegevus algab algkoolis. Kui laps käib nn täielikus algkoolis, jääb ta sinna alates 5. eluaastast kuni 12aastaseks saamiseni. Nn ettevalmistava algkooli korral peavad lapsed liikuma kaheks viimaseks algkooliaastaks ehk 11-12 ja 12-13 aasta vanuselt üleminekukooli. Keskkoolis käivad noored on 13-18aastased. Algkooli ja üleminekukooli õpilasi hinnatakse korrapäraselt, lähtudes nende vanuseastmele kehtestatud riiklikust standardist. Keskkoolis veedetud 
kolme viimase kooliaasta jooksul hinnatakse õpilaste teadmisi riigieksamite (NCEA) põhjal.

1989. aastast alates on Uus-Meremaa haridussüsteemi ulatuslikult reformitud, mille tulemusena on sellest saanud üks kõige enam detsentraliseeritud süsteem maailmas. Haridusministeeriumi ülesanne on kujundada üldist hariduspoliitikat ja koostada riiklik õppekava. Sõltumatult tegutsev haridusjärelevalveamet (Education Review Office) hindab iga kolme aasta tagant hariduse kvaliteeti kõigis 2532 koolis ja lasteaias. Ühtlasi avaldab haridusjärelevalveamet üleriigilisi aruandeid konkreetsete haridusteemade kohta, kasutades hindamise käigus kogutud teavet. Kõigil riigi- ja integreeritud koolidel on hoolekogud, kes vastutavad kooli juhtimise eest. Hoolekogu hoolitseb kogu kooli tööks vajaliku personali töölevõtmise, kooli strateegiliste eesmärkide väljatöötamise ning turvalise õppekeskkonna ja kõigile õpilastele kvaliteetse hariduse tagamise eest. Hoolekogu ülesanne on teha järelevalvet personali juhtimise, õppekava täitmise, kinnisvara haldamise, finantsjuhtimise ja kooli üldise juhatamise üle. Hoolekogu liikmeid valivad lapsevanemad, koolipersonal, ja kui koolis õpivad vanemad kui 9aastased lapsed, siis ka õpilased. Niisamuti on koolidirektor hoolekogu liige (Ministry of Education, 2015).

\section{Erivajadustega õpilaste toetusprogrammid ja tugiteenused}

Nii nagu valdavas osas teisteski riikides, on hariduslike erivajadustega lastele pakutavad haridusteenused ka Uus-Meremaal üsna keerulist laadi. Lühidalt öeldes pakutakse alg- ja keskkoolis kahte peamist teenust, mille valik oleneb sellest, millist toetust lapsed Uus-Meremaa õppekava läbimiseks vajavad. Kõige suuremate erivajadustega õpilased moodustavad 3\% kõigist koolis käivatest lastest ning neid toetatakse nelja programmi raames: 1) kestev ja pikendatav toetusskeem (Ongoing and Renewable Resourcing Scheme, ORRS) (1\% kõigist lastest), 2) käitumisalgatus (Behaviour Initiative), 3) suhtlemisalgatus (Communication Initiative) ja 4) raskete terviseprobleemidega laste koolitamine (School High Health Needs). Mõõduka kuni sügava puudega õpilasi toetatakse kuue programmi raames, sealhulgas 1) õpiraskuste ja käitumisprobleemidega laste tugiõpetajad (Resource Teachers: Learning and Behaviour, RTLBs), 2) eripedagoogika toetused (Special Education Grants) ja 3) mõõduka keha-, kuulmis- ja nägemispuudega laste toetus (Moderate Physical, Hearing and Vision Support) (Ministry of Education, 2010a). 


\section{Kaasava hariduse hindamine Uus-Meremaal}

Järgnevalt annan lühiülevaate muudes väljaannetes juba tutvustatud kaasava hariduse kriteeriumidest ning selgitan, millises ulatuses on need UusMeremaal täidetud.

\section{Kontseptsioon}

Kõigil süsteemi tasanditel töötavad pedagoogid järgivad pühendunult kaasava hariduse filosoofiat ja teevad ettepanekuid kaasava hariduse käsitlemiseks seadustes, määrustes ja poliitilistes dokumentides, mis mõjutavad kõiki haridussüsteemi tasandeid.

Üldiselt täidab Uus-Meremaa mitmesugustes riiklikul tasandil vastu võetud ametlikes dokumentides kehtestatud kriteeriume. Näiteks nähakse haridusseaduses (1989) ette, et „... (kas puude või muu põhjuse tõttu) hariduslike erivajadustega inimestel on samasugune õigus ennast riigikooli registreerida ja saada haridust nagu inimestel, kellel ei ole selliseid erivajadusi”. Samuti sätestatakse 1993. aastal vastu võetud inimõiguste seaduses, et on seadusevastane, kui haridusasutus või haridusasutust juhtiv võimuorgan või mõni isik, kes on seotud haridusasutuse juhtimise või seal õpetamisega:

a. keeldub isikut õpilaseks või üliõpilaseks võtmast või ei saa sellega hakkama;

b. võtab isiku õpilaseks või üliõpilaseks ebasoodsamatel tingimustel, kui selles haridusasutuses üldiselt tavaks on;

c. keeldub andmast juurdepääsu mis tahes hüvele või teenusele, mida see haridusasutus pakub, või piirab seda;

d. välistab isiku õpilase või üliõpilasena või kahjustab teda mõnel muul viisil, tehes seda mis tahes keelatud diskrimineerival põhjusel (mis hõlmab ka puuet).

Asjakohane on tsiteerida ka riiklikke haridussuuniseid, mille kohaselt peavad koolid tagama „võrdsed haridusalased võimalused kõigile uusmeremaalastele, tehes kindlaks ja eemaldades mis tahes takistused selle saavutamiselt" (Ministry of Education, 2009). Ühtlasi oli Uus-Meremaa üks esimesi riike, kus ratifitseeriti ÜRO puuetega inimeste õiguse konventsioon, mille artikkel 24 kohustab tagama kaasava hariduse (ÜRO, 2008).

\section{Paigutamine}

Enamik kaasava haridusega tegelevatest teadlastest väidab kas otseselt või kaudselt, et kaasamine tähendab kõigi õpilaste paigutamist tavakoolidesse 
ja -klassidesse, hoolimata nende võimekusest. Enamik neist väidab või viitab sellele, et kõiki erivajadustega õpilasi, olenemata nende võimetest, tuleb õpetada elukohalähedase kooli klassis, mis vastab nende eale.

2014. aastal kogutud andmete kohaselt oli Uus-Meremaal kooli registreerunute hulgas $1 \%$ suurte erivajadustega lapsi, kellest vaid 33,5\% sai haridust erikoolides. Ülejäänud $66,5 \%$ paigutati tavakoolide eri- või tavaklassidesse (sellise jaotuse kohta statistika puudub). 2010. aastal hindas haridusjärelevalveamet (Education Review Office, 2010) 199 algkoolist ja 30 keskkoolist koosnevat valimit, et teha kindlaks, mil määral kaasati neis koolides erivajadustega õpilasi, kelle õppimist rahastati ja toetati mitmesuguste mehhanismide kaudu. Umbes 50\% uuritud koolidest kasutati ühisõpet, 30\% koolides olid kasutusel nn ühisõppe üksused ja ülejäänud 20\% koolides kasutati ühisõpet väga vähe. Sellest uuringust ajendatult töötas valitsus välja tegevuskava hariduslike erivajadustega laste edasijõudmise, osalemise ja kohaloleku edendamiseks kõigis tavakoolides (Ministry of Education, 2010c). 2014. aastal 152 koolis korraldatud jätku-uuringu käigus leidis haridusjärelevalveamet, et 75\% koolidest rakendas kaasavat haridust. Selline osakaal oli üsna lähedane haridusministeeriumi (2010c) eesmärgiks seatud $80 \%$ le.

\section{Kohandatud õppekava}

Olen juba varem väitnud, et asjakohaste kohanduste ja muudatuste tegemine õppekavas on kaasava hariduse puhul möödapääsmatu (Mitchell, 2014). Seejuures olen rõhutanud, et kui vähegi võimalik, peaks ühtne õppekava olema kättesaadav kõigile õppuritele, sealhulgas neile, kellel on hariduslikud erivajadused. Ühtlasi peaks õppekava sisaldama eakohaseid tegevusi, mis vastavad õpilaste arengule. Kuna ühisõppeklassis võib olla õpilasi, kes järgivad kahe või kolme raskusastmega õppekava, tuleb õpetada eri tasemetel või teha vähemalt selliseid kohandusi, mis arvestaksid õpilaste eripärasid.

Erinevalt mõningatest riikidest, kus on eraldi õppekavad tavalistele ja erivajadustega õpilastele, on Uus-Meremaal ühtne õppekava. Uus-Meremaa õppekava sisaldab kaheksa peamise põhimõtte seas ühte kaasava hariduse jaoks eriti olulist põhimõtet: „Õppekava ei tohi olla seksistlik, rassistlik ega diskrimineeriv; õppekava tagab, et [kõigi] õpilaste identiteeti, keelt, võimeid ja andeid tunnustatakse ja aktsepteeritakse ning nende haridusalaseid vajadusi võetakse arvesse” (Ministry of Education, 2007, lk 9). Õpilasteks, kellel on „suured või väga suured erivajadused” (termin, mida eelistatakse termini puue asemel), loetakse neid, kellel on kindlaks tehtud, et 
„nad vajavad Uus-Meremaa õppekava omandamiseks ja/või selle õppekava sisu kohandamiseks spetsialistide ja/või eripedagoogide abi" (Ministry of Education, Eligibility Unit, 2004, lk 3). 2014. aasta seisuga moodustasid sellised õpilased 1,1\% kõigist koolis käivatest lastest. Arvatavasti tuleb nende õppekava sisu muuta erinevas ulatuses, alates kogu õppekava sisu täielikust muutmisest kuni suure osa õppekava sisu märkimisväärse muutmiseni, nii nagu on ette nähtud nende individuaalsetes õppekavades.

\section{Kohandatud hindamine}

Nii nagu hariduslike erivajadustega õpilastelt oodatakse üldises õppekavas osalemist ja edasijõudmist, olgugi et see on nende järgi kohandatud, oodatakse neilt ka üha sagedamini osalemist üleriigilistel või piirkondlikel hindamistel. Põhimõtteliselt tehakse üleriigilistesse ja piirkondlikesse hindamiskavadesse kahte liiki kohandusi. Esiteks, kohandatud hindamine hõlmab muudatuste tegemist hindamisprotsessis, kuid mitte hindamise sisus. Sellised kohandused tähendavad muudatusi toimumiskohas ja -ajas, hindamise korraldamises ja vastuste tüüpides. Teiseks kasutatakse alternatiivset hindamist, mida määratletakse kui hindamist, „mis on kavandatud nii, et see sobiks väikesele puuetega õpilaste rühmale, mille liikmed ei ole võimelised osalema tavapärasel riiklikul hindamisel isegi juhul, kui seda on asjakohaselt kohandatud" (U.S. Department of Education, 2003, lk 68699). Sellisel juhul põhineb hindamine eri olukordades kogutud materjalidel, sealhulgas õpetajate tähelepanekutel, näidistel õpilaste töödest, mis on valminud tavalise tunni käigus ja tavapäraste ülesannete täitmisel.

Uus-Meremaal kinnitab Uus-Meremaa eksamikeskus hindamise eritingimused (Special Assessment Conditions, SACs), mille alusel pakutakse riigieksamite ajal lisaabi erivajadustega keskkooliõpilastele. Selline lisaabi tähendab eelkõige eespool mainitud kohandatud hindamist. Hindamise eritingimuste eesmärk on kõrvaldada edasijõudmist takistavad asjaolud, pakkudes erivajadustega õpilastele võrdset võimalust hinnete saamiseks, andmata neile teiste kandidaatide ees mingeid eeliseid. Näiteks lubatakse neil kasutada abivahendeid lugemiseks ja kirjutamiseks või arvutit, võtta puhkepause, kasutada Braille' kirja või suurendatud kirja. Sellise kohtlemise osaliseks saavad õpilased, kellel on püsiv või pikaajaline meditsiiniline, keha- või meelepuue ja/või õpiraskused, mis otseselt mõjutavad nende võimet läbida õiglast hindamist (New Zealand Qualifications Authority, kuupäev puudub).

Alg- ja põhikooli tasandil eeldatakse, et enamik hariduslike erivajadustega õpilasi on võimelised saavutama riiklikele standarditele vastavaid 
tulemusi ning nende arengut ja saavutusi kajastatakse kõnealuste standardite põhjal. Siiski võidakse korraldada alternatiivne hindamine õpilastele, keda rahastatakse kestva ja pikendatava toetusskeemi alusel ning kelle pikaajaline õppimine jääb Uus-Meremaa óppekava kohaselt vaid esimesele tasandile. Selliste õpilaste edasijõudmist ja standarditele vastavust hinnatakse nende individuaalse õppekava raames. Õpetajad võivad kasutada mitmesuguseid hindamisvahendeid ja -viise, sealhulgas kirjeldavat hindamist ja lugusid õppimise kohta, et esitada põhjalik ülevaade õpilase oskustest, tugevatest külgedest ja tugiteenustest, mida õpilane vajab (Ministry of Education, 2010b).

\section{Kohandatud õpetamine}

Pedagoogidelt oodatakse üha sagedamini, et nad mitte üksnes ei aitaks õpilastel saavutada võimalikult häid õpitulemusi, vaid kasutaksid sel eesmärgil meetodeid, mis on teaduslikult kõige paremini põhjendatud. Ameerika Ühendriikides nõutakse lausa laste võrdsete võimaluste seadusega („No child left behind law"), et õpetajad kasutaksid „teaduslikke, uuringutel põhinevaid programme”, mis on „1) teoreetiliselt põhjendatud; 2) kolmandatelt pooltelt hinnangu saanud; 3) avaldatud eelretsenseeritavates ajakirjades; 4) jätkusuutlikud; 5) asendatavad koolides, kus õpilaskond on mitmekesise taustaga; 6) tõestatava tõhususega”. 2014. aastal ilmunud raamatus (Mitchell, 2014) tutvustan umbes 27 strateegiat, mille positiivne mõju hariduslike erivajadustega õpilaste õpitulemustele on korduvalt tõestatud.

Uus-Meremaal on minu raamat laialdaselt kasutuses. Näiteks on see kohustuslik lugemisvara Canterbury Ülikooli õpiraskuste ja käitumisprobleemidega laste tugiõpetajate koolitusel, samuti kasutatakse seda haridusministeeriumi parimate tavade sünteesimise programmis, mille alusel kujundatakse hariduspoliitikat ja -tavasid (Alton-Lee, 2003; Ministry of Education, kuupäev puudub).

\section{Aktsepteerimine}

Haridussüsteem ja kool tunnustavad hariduslike erivajadustega õpilaste õigust õppida tavakoolis ja saada selleks vajalikku toetust. Aktsepteerimine ei tähenda üksnes seda, et tunnustatakse selliste õpilaste õigusi, vaid ideaalne oleks, kui õpetajad ja teised õpilased aktsepteeriksid inimeste mitmekesisust filosoofilisel tasandil ja võtaksid hariduslike erivajadustega inimesed nii suhtlustasandil kui ka emotsionaalses mõttes omaks. Siinkohal võib kindlalt väita, et kaasava hariduse aktsepteerimine on Uus-Meremaal laialt levinud, kuid mitte täielik. 


\section{Juurdepääs}

Juurdepääs on väga lai valdkond, mis hõlmab juurdepääsu haridusele, kohandatud õppekavale ja hindamisele (mida käsitlesin eespool) ning sobivat füüsilist juurdepääsu klassiruumidele ja seal liikumise võimalust. Viimane tagatakse selliste abivahenditega nagu kaldteed ja liftid, kohandatud tualettruumid, ukseavad, mis on ratastoolide jaoks piisavalt laiad, ning klassiruumid, kus on küllalt ruumi ratastooliga liikumiseks. Füüsilise juurdepääsu võimaldamisel tagatakse, et kõik siseruumide komponendid, mis võivad mõjutada õpilase õppimisvõimet, oleksid optimaalsed. Silmas tuleb pidada mööbli disaini ja paigutust, akustikat, valgustust, temperatuuri, õhu kvaliteeti ja turvalisust.

Uus-Meremaa standardite (2001) kohaselt tuleb ehitiste (sealhulgas koolide) „projekteerimisel lähtuda ligipääsetavuse, kättesaadavuse ja kasutatavuse põhimõttest, mis tagavad, et puuetega inimesed, külastajad ja töötajad saaksid ehitistesse siseneda ja seal oma tavapärasel viisil tegutseda ja töötada ..." (lk 16). See tähendab, et pärast konsulteerimist kooli hoolekogu ja õpilase hooldajaga rahastab haridusministeerium mis tahes mõistlikke ümberehitustöid (näiteks kaldteed, pesemisvõimalused, liftid), mille abil tagatakse kehapuudega õpilaste juurdepääs kooliruumidele.

\section{Toetus}

Hariduslike erivajadustega õpilaste õpetamine eeldab koostööd paljude inimeste, eelkõige mitmete asjatundjate ja vanemate vahel. Hariduses on vähe valdkondi, mis nõuavad sama palju meeskonna- ja koostööd. Eriti tuntav on see kaasava hariduse puhul, kus ideaalis teevad tavalised õpetajad koostööd mitmesuguste rühmadega, millesse kuuluvad eripedagoogid, abiõpetajad, tugiteenuste nõustajad, hariduspsühholoogid, terapeudid ja muud spetsialistid ning ühiskondlikud asutused, näiteks hoolekandeasutused, politsei ja advokatuuri esindajad, tehnoloogiakonsultandid ja muidugi lapsevanemad.

Kui Uus-Meremaal on mõnel lapsel „suured või väga suured erivajadused", siis rahastab haridusministeerium otse mitmete programmide ja teenuste kaudu nende erivajaduste rahuldamist. Selliste programmide hulka kuuluvad 1) kestev ja pikendatav toetusskeem, mis toetab suurte või väga suurte erivajadustega lapsi, andes neile lisaõpetajad, tugiisikud, spetsialistid ja vahendid, mida laps võib koolis vajada; 2) suhtlemisteenus, millega toetatakse lapsi, kellel on raskusi rääkimise, kuulamise ja keele mõistmisega; 3 ) raskete käitumishälvete teenus, millega toetatakse raskete käitumishälvetega lapsi, ja 4) raskete terviseprobleemidega laste haridusfond, mille kaudu määratakse tugiisikud lastele, kes vajavad oma 
terviseseisundi tõttu erihooldust, et turvaliselt koolis käia. Tavaõpetajatele on abiks ka 1) hariduslike erivajaduste koordinaator (Special Education Needs Coordinator, SENCO), kes võib koostöös vanemate ja õpetajaga koostada lapsele sobiva programmi, ja 2) teised ópetajad, tugiisikud või muud teenused ja toetusprogrammid, mida kool ostab talle määratud erihariduse toetuse kaudu, mille suurus sõltub laste arvust ja kooli kohast väiksemate võimalustega laste integreerimise pingereas, ning 3) õppimise ja käitumise tugiõpetajad, keda palkavad koolide klastrid, et pakkuda tavakooli õpetajatele eripedagoogikas kasutatavaid strateegiaid või algatada kogu kooli hõlmavaid programme.

\section{Ressursid}

Et rakendada siinses artiklis kirjeldatud kaasavat haridust, mis eeldab mitmekülgset lähenemist valdkonnale, on kindlasti tarvis piisavalt ressursse. Sellised ressursid peavad katma ehitiste, abivahendite, transpordi ja personaliga seotud kulud. Viimase kümnendi jooksul on hariduslike erivajaduste rahastamise mudeleid paljudes riikides muudetud, sest kulud kasvavad üha enam ja tuntakse muret ressursside kasutamise tõhususe ja põhjendatuse ning vastuoluliste tavade rahastamise tulemuslikkuse pärast.

Uus-Meremaal eraldatakse vahendeid kahel viisil. Esimese süsteemi puhul tehakse kindlaks need ligikaudu 3\% õpilastest, kes vastavad haridusministeeriumi kehtestatud kõige suuremate vajadustega õpilaste kriteeriumidele. Ministeeriumi ülesanne on määrata kindlaks, millises ulatuses ja mis laadi toetust kõnealused õpilased vajavad, ning eraldada asjakohased vahendid. 1980. aastal tehti kaasamise hõlbustamise seisukohalt oluline otsus, mille kohaselt peaksid vahendid käima õpilasega kaasas, hoolimata sellest, kas ta õpib eri- või tavakoolis. Varem eraldati erivajadustega õpilastele lisavahendeid enamasti üksnes juhul, kui nad õppisid erikoolis. Uus süsteem on rahvastikupõhine, mille kohaselt saavad koolid erihariduse toetust vastavalt erivajadustega laste arvule ja teeninduspiirkonna sotsiaalmajanduslikule olukorrale. Eeldatakse, et need toetused on piisavalt suured ja katavad lisakulutused, mis on vajalikud mõõdukate erivajadustega õpilaste õpetamiseks.

\section{Juhtimine}

Positiivse koolikultuuri ehk eetose loomiseks on tarvis välja töötada kooli eesmärgid ja need ellu viia. Neis eesmärkides peaksid sisalduma väärtused, tõekspidamised, hoiakud, traditsioonid ja käitumisnormid, mida kogu koolipere, eelkõige kooli juhtkond, soovib jagada. Sellist juhtimisviisi 
tuleks kasutada kogu haridussüsteemis: seda peaksid tegema seadusandjad, poliitikakujundajad, kooli hoolekogud, direktorid ja õpetajad. Carrington, Bourke ja Dharan (2012) on kirjeldanud kooli juhtimist direktori tasandil kui „pöördelise tähtsusega tegevust, mis nõuab temalt töötajate mõistmist, neisse uskumist ja nende kaasamist" (lk 351).

Haridusjärelevalveamet (2015) märkis 2014. aastal Uus-Meremaa koolides erivajadustega õpilastele pakutava kaasava hariduse võimalusi uurivas ülevaates, et „kaasavate koolide juhtidel on suured ootused seoses õpilastega ning nad on taganud, et nende töötajad mõistavad oma ülesannet vastata kõigi õpilaste vajadustele". Oma varasemas aruandes leidis haridusjärelevalveamet (2010), et erinevused koolide kaasamise tasemes sõltusid pigem juhtimise kvaliteedist kui rahastamisest.

\section{Kokkuvõte}

Kaasav haridus on mitmetahuline mõiste, mis nõuab pedagoogidelt kõigil haridussüsteemi tasanditel tegelemist kontseptsiooni, paigutamise, õppekava, hindamise, õpetamise, aktsepteerimise, juurdepääsu tagamise, toetamise, ressursside ja juhtimisega. Uus-Meremaa vastab kõigile nendele kriteeriumidele kõrgel tasemel.

\section{Kasutatud kirjandus}

Alton-Lee, A. (2003). Quality teaching for diverse students in schooling: Best evidence synthesis iteration (BES). Wellington: Ministry of Education. Retrieved from https://www.educationcounts.govt.nz/__data/assets/pdf_file/0019/7705/BESquality-teaching-diverse-students.pdf.

Carrington, S., Bourke, R., \& Dharan, V. (2012). Using the Index for Inclusion to develop inclusive school communities. In S. Carrington \& J. MacArthur (Eds.), Teaching in inclusive school communities (pp. 343-364). Milton: Wiley.

CIA (2015). The world factbook. Retrieved from https://www.cia.gov/library/publications/the-world-factbook/.

Education Review Office (2010). Including students with high needs. Wellington. Retrieved from http://www.ero.govt.nz/assets/Uploads/Including-Students-withHigh-Needs-2010-pdf-with-cover.pdf.

Education Review Office (2015). Inclusive practices for students with special needs in schools. Wellington. Retrieved from http://www.ero.govt.nz/assets/Uploads/Inclusive-practices-for-students-with-special-needs-in-schools.pdf.

Ministry of Education (2007). The New Zealand Curriculum. Wellington. Retrieved from http://nzcurriculum.tki.org.nz/content/download/1108/11989/file/The-NewZealand-Curriculum.pdf.

Ministry of Education (2009). The national education goals. Wellington. 
Ministry of Education (2010a). Review of Special Education 2010 discussion document. Retrieved from http://workbridgeincorporated.virtuozzo.co.nz/OtherDocuments/ReviewOfSpecialEducation_17Mar10.doc.

Ministry of Education (2010b). Through different eyes. Wellington. Retrieved from http://www.throughdifferenteyes.org.nz/.

Ministry of Education (2010c). Success for all - every school, every child: Building an inclusive education system. Wellington. Retrieved from http://www.education. govt.nz/assets/Documents/School/Inclusive-education/SuccessForAllEnglish.pdf.

Ministry of Education (2015). Education counts. Retrieved from https://www.educationcounts.govt.nz/data-services/data-collections/national/boards_of_trustees.

Ministry of Education (nd). BES (Iterative Best Evidence Synthesis) Programme What works evidence. Retrieved from https://www.educationcounts.govt.nz/topics/BES.

Ministry of Education, Eligibility Unit (2004). The Ongoing and Reviewable Resourcing Schemes guidelines. Wellington.

Mitchell, D. (2014). What really works in special and inclusive education (2nd ed.). Abingdon: Routledge.

Mitchell, D. (2015). Inclusive education is a multi-faceted concept. Center for Educational Policy Studies Journal, 5(1), 9-30.

New Zealand Qualifications Authority (nd). Special assessment conditions. Wellington: David Mitchell. Retrieved from http://www.nzqa.govt.nz/providers-partners/ assessment-and-moderation/managing-national-assessment-in-schools/specialassessment-conditions/.

Standards New Zealand (2001). Design for access and mobility - Buildings and associated facilities. Retrieved from http://www.standards.co.nz/assets/Publication-files/NZS4121-2001.pdf.

U.S. Department of Education (2003). Title I - Improving the academic achievement of the disadvantaged. Final Rule, 68 Federal Registry 236.

ÜRO (2008). Convention on the Rights of Persons with Disabilities. New York. Retrieved from http://www.un.org/disabilities/convention/conventionfull.shtml. 